But the important question still remains to be determined-a question upon which the cases $I$ have just detailed throw no sort of light-namely, what circumstances forbid lithotrity? It may be stated, as a general fact, that in calculous patients the bladder is not unfrequently found in one of two opposite states, which, if they do not absolutely forbid lithotrity, render its application in the highest degree dangerous, and (as a remedial means) far inferior to cystotony. The bladder, like the stomach and the heart, has not inaptly been termed a "hollow muscle," which is constantly receiving and transmitting a fluid; like the heart, it is liable to hypertrophy, or thickening of its walls, diminution of its capacities, and increased irritability, or power of contraction; like the heart, too, it is subject to a thimning of its walls, an increase of its capacity, and a diminution of its contractile power: these opposite conditions are easily recognised, and are familiar to every surgeon of experience; but to $M$. Civiale is due the merit of having shown the influence which these states of the bladder exercise on the success of lithotrity. In the hypertrophied bladder, the patient is harassed by the almost in cessant desire to pass water; the quantity discharged seldom exceeds an ounce, or an ounce and a half; the pain, especially in expelling the last drops, is excessive; the urine is always high-coloured, and deposits, on cooling, a mucous sediment, frequently tinged with blood. In such a case, the mere operation of sounding, or even of injecting warm water into the bladder, may excite a severe or even fatal inflammation of the organ. I have knowledge of two cases in which the injection of tepid water into the bladder (thongh done with the utmost care) proved fatal in three days, by exciting acute inflammation of that organ; on examination after death, the mucous membrane was found inflamed, thickened, and corrugated. In such a state of the bladder, it is scarcely necessary to say that lithotrity is not to be thought of.

The opposite state, in which there is atrophy or wasting of the walls of the viscus, with increase of its capacity (M. Civiale justly observes), exercises a great influence on the sensations which are caused by a calculus as well as upon the manceuvere of the operation, and on its result; it masks all the symptoms of stone, or renders them different from those we are accustomed to observe. As the bladder never empties itself com pletely, its walls scarcely come in contact with the stone; the consequence is, that the pain and the peculiar sensation in expelling the last portion of the urine (the most certain of the rational symptoms of stone) are wanting. Exercise does not cause those bleedings from the bladder, and those painful spasms, of which calculous patients, under other circumstances, complain so much; the urine is loaded, foetid, and alkaline, the debility increases daily, the pulse is quick and weak, and there are frequent chills, followed by heat flushes - the bladder is in a state of low inflammation, with diminished vital powers, and the kidneys generally participate in the disease. In such.a state of things, M. Civiale justly considers that the operation of lithotrity would almost certainly prove fatal; but I believe the same might be said, with equal truth, of cystotomy. He thinks it of so much importance, with reference to lithotrity, that this condition of the bladder should be clearly understood, that, in addition to the signs above mentioned, he gives several others that are deserving of the utmost attention. This morbid thinning and atony of the walls of the bladder must not be confounded with paralysis, or want of action from defect of invervation; this last state furnishes no objection to the application of lithotrity, provided sufficient means be employed to rid the bladder of the fragments of the broken calculus. This is well illustrated by one of my own cases, where the bladder was so completely paraIyzed, that for several years the patient had been obliged to draw off the urine by the catheter four or five times in the day.

In addition to the morbid states of the bladder described by M. Civiale, I should say that a contracted and irritable urethra, an enlarged and irritable prostate gland, and, above all, a constitution prone to sympathize with a disordered state of the urinary organs in general, and with the urethra in particular, a large and very hard stone, or numerous small ones, forbid the application of lithotrity, and bring the case within the proper domain of cystotomy.

Lithotrity is in general considered as inapplicable to children under fifteen or sixteen years of age, on account of the narrowness of the urethra in early life, and the comparative safety of cystotomy in young subjeets; but considering that in children the urethra is (except at its external orifice) highly dilatable, and that the most violent symptoms of calculus in the bladder are often created by the presence of a stone so small that it might with the greatest faciity be crushed, and the fragments extracted, at a single operation, I cannot but hope, that at no distant period the operation of cystotomy will be superseded by lithotrity, in a great proportion of cases of calculus in children. I think that these four calculi [showing them] which $I$ have extracted from infants under six years of age, are the last of the kind that $I$ shall either extract or see extracted by that painful and dangerous operation. But a few days since, Mr. Cusack performed cystotomy on a child of four years of age, in Steevens' Hospital; the moment he divided the membranous part of the urethra, the stone started out into the external incision, and was removed by the fingers of the operator; only the membranous part of the urethra had been opened; the prostate and bladder were untouched. What a triumph it would have been for lithotrity, and what an advancement in operative surgery, if lithotrity had been applied to this case. The bladder not having been opened, the wound was healed in three or four days, and the child was perfectly cured. Nevertheless, it is impossible not to regret, for the sake of the advancement of operative surgery, which is immeasurably improved by everything that renders operations more safe and less painful, that lithotrity had not the merit of this cure.

\section{ON THE EXPULSION OF ENTIRE OVA.}

By J AMrs Macreness, Esq., M.D., Hastings.

A TWIN, APPARENTLY STILL-BORN, ANTMATED BY LONG-CONTINOED FRICTYONS, ETC.

Two or three cases have lately been reported in your columns where the ova have been expelled entire. The following case of ova being expelled entire is somewhat singular:-

I had been attending a lady, staying at St. Leonard's, for some slight illness. During the latter part of the month of August last, she was far advanced in pregnancy. On the night of the first of September, her husband called me up, and told me that his wife was much indisposed, but that he did not think she was in labour. On entering the room, a friend of the patient who was with her, said, "Doctor, it is all over; the child has been born these ten minutes or quarter of an hour, but it has not cried, nor have I looked at it." On making an examination, I found an ovum entire. I broke the membranes, tied the cord, and gave the child to the attendant, while I paid a little attention to the mother. To my surprise, I found another ovum, also entire, from which I extracted another infant. Both appeared to be still-born, and my efforts were immediately directed to excite the function of respiration by inflating the lungs, dashing cold water over their bodies, wiping them dry, and having their skins well rubbed. By assiduously employing these means for about a quarter of an hour or twenty minutes, I had the satisfaction of seeing both infants show signs of animation, and having by this time got a fire lighted, and exposing them to its warmth, they both cried out very lustily. There was no hæmorrhage, and the placenta of each child was separate.

There are three points which claim our consideration in this case.

1st.- The length of time which had elapsed from the expulsion of the ova, and my arrival at the house.

2ndly.-The success which resulted from the persevering efforts employed to arouse the vital powers.

3 rdly.-The absence of flooding after the expulsion of entire ova.

Ten or fifteen minutes were alloged to have passed from the expulsion of the ova and my arrival, and although it is quite possible that the impatience and anxiety of the patient and her friend might have somewhat over-calculated the time, yet, from other accompanying circumstances, I do not think they had much exaggerated. Dr. Campbell, the lecturer on midwifery at Edinburgh, used to relate a case where a young student of midwifery had for one of his earliest patients a case where the ovim was expelled entire, and not being prepared for such an event, and not understanding it, became alarmed, liastily ran for the lecturer, who returned with him to extract a child from the ovum, which had thus negligently died from asphyxia.

2nd.-The means which I adopted had in them nothing unusual, except that I had nothing but cold water and the employment of artificial respiration at my command. It is true that Dr. Blundell, in his "Principles and Practice of Obstetricr," says, page 246,1834

"Of the various practices recommended for the resuscitation of still-born children, I may observe, there are two on which I place a principal reliance, and which I would recommend you to urge with diligence, not, however, 
excluding the subordinate remedies, and these two remedies are, the artificial respiration and the warm bath." And again in the same page, he says, " "The artificial respiration should be diligently tried, indeed, if this and the warm bath fail us, I know of no other resuscitants on which we can confidently rely." For my own part, I have always found a shock from a dash of cold water more efficacious in rousing the vital powers than warm, but where warm water is ready at hand, I have found a sudden dash of cold water, alternating with a plunge into the warm bath, more efficacious than either alone; and, in my opinion, this plan, combined with friction and artificial respiration, kept up ior a considerable time, will give the greatest chance for success. In this case, cold water only was at my command, for it was in the middle of the night, and labow had unexpectedly come on. I alternately dashed cold water over each of the infants, wiped them dry, and, while the nurse was employing friction with the warm hand on one, I was inflating the lungs of the other. The same process was repeated for several times on each, until at length $I$ had the great satisfaction to hear one of them ntter a faint cry, and the other a sob; still continuing my effor's, they both cried out lustily, and are now living.

This is an instance where complete success attended persevering efforts to resuscitate still-born children, and may well encourage others not to relax their efforts until a probability of doing so no longer exists.

Flooding very frequently accompanies the expulsion of the entire orum; in this case it did not take place. I do not now usually practise midwifery, but at one period of my life $I$ had much of this practice, and I have occasionally had cases where, in the sixth or seventh month of pregnancy, the ovum has been passed entire; most generally I have found this event accompanied by considerable hæmorrhage. Dr. Blundel says, also, "Principles of Obstetricy," p. 234- "In the sixth and seventh month especially, the ovum tends to come away unbroken, like the egg of an ostrich, and when this is the case much flooding may occux, and the child will most probably be drowned, as it comes into the world immersed in a bag of water, and may perish." Again, "Should the laxity of the parts, or the capacity of the pelvis, allow of the transmission of the membranes entire, Hoodings fatal to the mother and destructive to the fotus may be the result." The lady in this case was, according to her reckoning, a little more than the seventh month of pregnicy; this was her second confinement, and she not only had no flooding, but not a single untoward symptom : the intants, although small, appeared fully seven months' children.

Hastings, January, 1846.

\section{REVIES.}

Elements of Materia Medice and Therapeutics. By Edward Ballard, M. D., Lond., and Alfred Baring Garrod, M. D., London. Taylor and Walton. 1845. pp. 447 .

THe enumeration of the divisions treated of by each author will convey an idea of the plan of the present work. The Therapentical Introduction, the Vegetable Materia Medica, the Animal Materia Medica, and the article on General Bloodletting, with the Appendix, are by Dr. Ballard; while the Chemical Introduction, the Inorganic Materia Medica, and the article on Electricity, are written by Dr. Garrod.

This work we do not hesitate to say is a very valuable contribution to educational medical literature. The department of Materia Medica has been too much overladen with ponderous tomes of a thousand pages, a circumstance by no means conducing to the advance of the student or the interests of the profession. Overgrown works of this kind only tend to elevate into undue importance the study of drugs, and to obstruct the student in his way to the higher branches of medical science. Large worlis are valuable for reference; but we believe the feeling which at present obtains, both among teachers and students, is in favour of more concise manuals on phamacy and materia medica.

It is no more for the good of the student to pore over an overgrown book on the materia medica, than it is to spend five years of appreaticeship in compounding physic. Another advantage in the work of Drs. Ballard and Garrod is, that they have brought the most recent knowledge in the other departments of medical science to bear fully on therapeutics.
In the therapeutical introduction, Dr. Ballard has done something towards breaking up the old arbitrary arrangements, and he might have gone still further with safety in the same direction. Even to the superficial observer it will be seen, that for the past few years medical science has been advancing rapidly by two great routes, Neurology representing the one, Organic Chemistry the other. Neurology must be placed first, since it constitutes the chief branch of $d y$ namics, of the imponderable agents in physiology; while Organic Chemistry chiefly deals with the ponderable substances.

Bell was stung to the commencement of his career of discovery by the taunt of the chemists of his day-that the old methods of investigation were exhausted. It is fashionable for Chemistry to use the same language now, and with equal injustice, since so much has been done by Hall. Dynamic and organic progress must both continue, till physiology, the knowledge of the animal Cosmos, has reached its final limit.

The remarkable discovery of Liebig, that there is a distinct relation between the composition of the vegetable alkaloids, quina, brucia, morphia, \&c., and the composition of the substance of the brain and nerves, and between these and no other elements, as far as can at present be shown, is adduced; this, and the corollary, that they may be "supposed to take a share in the formation of new, or the transformation of old brain and nervous matter," are among the most interesting points in modern therapeutics. On another action of these bodies, the following passage is worthy of attention:-

"In considering the mode in which remedies of this class alter the quantity of a secretion, or modify its chemical composition, two principal circumstances must be kept in view. It must be recollected, that the secreting organs are merely the agrents by which the material is separated from the blood; and the amoun 5 of the secretion will depend on the circulation through them, and the healthy state of their nervous supply. The separated matters themselves, however, do not originate here, they are derived from the transformations of tissue which are constantly proceeding, with greater or less rapidity, in the body at large. Medicines, therefore, which affect secretion, must do so in one of two ways: either they must act upon the nervous centres, increasing or diminishing their infuence upon the organs, and modifying the circulation through them, or, in the words of Liebig, "they must take a direct share in the change of matter in the body' or, 'exert an influence on the formation, or on the quality of a secretion, by the addition of their elements." "-p. 6 .

The nature of the nervous actions induced by various remedies, and the therapeutic action of the vis nervosa, are not so specifically referred to as they might with propriety have been; though much more information on these points is dispersed throughout this volume than we have seen in other works of the kind. We propose briefly to follow Dr. Ballard through some of his notices of the different classes of remedies.

Stimulants.- These are of particular organs, or of the whole system, diffusible stimulants, as ammonia, and specific stimulants, as copaiba:--

"But of all the remedies which can be denominated stimu. lant, strychnia and brucia are the most decidedly specific in their action ; for while their excitant influence is most powerfully exerted apon the excito-motory function of the spinal cord, we are not aware of their manifesting any operation at all, either upon the rapidity of the pulse, the energy of the mental functions, or the general temperature of the body. There are, doubtless, some who would look upon this as sufficient ground for denying them a place in the class of stimulants at all; but so far from agreeing with them in this respect, we regard the alkaloids of nux vomica as presenting the very simplest type of an excitant drug; and we do not hesitate to express our deliberate conviction, that every stimulant which augments the activity of the general functions of the bodv, does so by the influence, primary or secondary, which it exerts on the cerebro-spinal centres. We would even be disposed to go a step further, and to hope that the time is not far distant, when tonics, and some of the diaphoretics, purgatives, diuretics, and emmenagogues will be removed from their present unnatural connexions, and put side by side with strychnia, in the class under our notice." 